$\odot$
OPEN ACCESS

EDITADO POR

Raquel Freitag (PPGL/UFS)

REVISADO POR

Isabel de Oliveira e Silva

Monguilhott

SOBRE OS AUTORES

Silvana Silva de Farias Araújo

Contribuiu com Manoel

Crispiano Alves da Silva. Papéis: conceptualização, investigação, metodologia, supervisão, escrita

- rascunho geral, escrita análise e edição.

Manoel Crispiano Alves da Silva Contribuiu com Silvana Silva de

Farias Araújo. Papéis: conceptualização, investigação, metodologia, administração do

projeto, escrita - rascunho geral, escrita - análise e edição.

DATAS

Recebido: 13/05/2020

Aceito: 20/05/2020

Publicado: 27/06/2020

COMO CITAR

Araújo, S. S. F.; Silva, M. C. A.

(2020).

A heterogeneidade linguística e social na sala de aula: reflexões

para um ensino pautado na ciência. Revista da Abralin, v. 19,

n. 2, p. 1-5, 2020.
RESENHA

\section{A heterogeneidade linguística e social na sala de aula: reflexões para um ensino pautado na ciência}

\author{
Silvana Silva de Farias ARAUJO (1) \\ Universidade Estadual de Feira de Santana (UEFS) \\ Manoel Crispiniano Alves da SILVA 『 \\ Universidade Estadual de Feira de Santana (UEFS)
}

\section{RESUMO}

A conferência proferida pelo professor Doutor Carlos Alberto Faraco teve como objetivo primordial apresentar as bases de uma Pedagogia da Variação Linguística. O conferencista defendeu que o professor de Línguas Portuguesa precisa trabalhar o fenômeno da variação linguística não de uma forma "folclorizada e cosmética", como algo que ocorre apenas no falar rural, mas levar os alunos a compreenderem que a língua é uma realidade essencialmente heterogênea e essa heterogeneidade é funcional e intrínseca às línguas humanas, sendo condicionada por fatores sociais, geográficos, históricos e culturais, isto é, o professor tem que realizar um ensino de língua materna não pautado em dogmas, mas na ciência.

\section{ABSTRACT}

The conference delivered by Professor Doctor Carlos Alberto Faraco had as main objective to present the bases of a Pedagogy of Linguistic Variation. The speaker argued that the Portuguese Language Teacher needs to work on the phenomenon of linguistic variation not in a "folkloric and cosmetic" way, as something that occurs only in rural speech, but to lead students to understand that language is an essentially heterogeneous reality and this heterogeneity is functional and intrinsic to human languages, being conditioned by social, geographic, historical and cultural factors, that is, 


\section{REVISTA DA ABRALIN}

the teacher has to teach the mother tongue not based on dogmas, but on science.

\section{PALAVRAS-CHAVE}

Variação linguística. Ensino de Língua Portuguesa. Sociolinguística.

\section{KEYWORDS}

Linguistic variation. Portuguese Language Teaching. Sociolinguistics.

\section{Introdução}

A presente resenha discorre sobre a conferência promovida pela Associação Brasileira de Linguística (ABRALIN), exibida no dia 08 de maio de 2020, às 19 horas, de forma virtual, como uma das atividades da programação do evento ABRALIN AO VIVO, ocorrido durante o período de distanciamento social, provocado pela pandemia do novo coronavírus. A conferência, intitulada Bases para uma Pedagogia da Variação Linguística, foi proferida pelo Professor Doutor Carlos Alberto Faraco e moderada pela Professora Doutora Raquel Meister Ko. Freitag, docente da UFS e vice-presidente da ABRALIN. Faraco é professor titular aposentado da UFPR e possui doutorado em Linguística pela University of Salford (1982) e dentre os temas de seu interesse de investigação está o ensino de Língua Portuguesa na Educação Básica.

Apesar do avanço científico no campo dos estudos linguísticos e, em especial, da Sociolinguística, ainda permeia no cotidiano escolar, uma concepção de língua ideal, isto é, uma língua homogênea, que, como pontuou o conferencista, só existe "num determinado imaginário social". Para romper com essa visão, o pesquisador propõe a necessidade de existir uma "pedagogia da variação linguística", na qual deve ser inserido o fenômeno da variação nas aulas de Língua Portuguesa não de uma forma "folclorizada e cosmética", ou seja, não devendo ser vista como algo que acontece apenas na fala de indivíduos da zona rural. O Professor Faraco acrescentou que, se for para tratar a heterogeneidade linguística dessa forma, o preconceito linguístico será perpetuado, sendo assim preferível que o professor a deixe de fora das suas aulas. Faraco advoga que o ensino de língua materna, para desenvolver as habilidades leitora e de escrita do aluno, requer outras pedagogias que se inter-relacionam: pedagogia da oralidade, da leitura, da produção de texto e da gramática, todas entrelaçadas pela da variação linguística.

A pedagogia da variação linguística tem o objetivo de levar os alunos a compreenderem que a língua é uma realidade essencialmente heterogênea e essa heterogeneidade é funcional e intrínseca às línguas humanas, sendo condicionada por fatores sociais, históricos e culturais. O conferencista está propondo um ensino de língua pautado não em dogmas, mas na ciência. Assim, cabe ao docente mostrar que a língua, enquanto uma instituição social, reflete a diversidade e as contradições que existem 


\section{REVISTA DA ABRALIN}

em uma sociedade que, no caso do Brasil, é profundamente partida, marcada por uma brutal concentração de renda e manutenção de privilégios. A polarização sociolinguística brasileira legitimou, no plano da língua, as contradições sociais que marcaram a sócio-história do Brasil: de um lado, a norma de prestígio, e, de outro, o português falado pelos povos marginalizados socialmente (LUCCHESI, 2015).

Para o conferencista, um ensino de língua, pautado na referida pedagogia, deve mostrar a realidade sociolinguística brasileira e levar o aluno a compreender os fatores sócio-históricos que fizeram com que haja no Brasil uma norma valorizada e outra estigmatizada. Nessa perspectiva, defende um ensino não mais pautado na transmissão descontextualizada de regras gramaticais anacrônicas e artificiais, mas uma educação linguística interdisciplinar, tendo o regente a tarefa de explicar as circunstâncias sócio-histórico-culturais que levaram à legitimação de uma norma em detrimento da outra.

Para Faraco, uma compreensão consistente da variação incide na exploração dos múltiplos fatores condicionantes da heterogeneidade, sendo, um deles, a história demográfica. Isso significa dizer que o docente precisa apresentar aos discentes como se formou, historicamente, essa "sociedade partida" e as implicações linguísticas dessa partição. Nesse contexto, é peremptório os alunos entenderem que o projeto colonial português, que perdurou por quase quatro séculos no país, se deu na exploração da mão de obra escravizada e o extermínio da população autóctone.

Nessa circunstância histórica, o português foi adquirido de forma assistemática, "de oitiva", sendo profundamente modificado, nativizado com marcas dos intensos contatos linguísticos. Segundo Mattos e Silva (2004), essa variedade, que apresenta efeitos do seu processo de aquisição precária, é o antecedente histórico do português popular brasileiro.

Após a libertação oficial da escravatura, em 1888, o grande contingente dos ex-escravizados não foi assistido pelo Estado brasileiro com políticas públicas de reparação, como acesso à escola, tendo que conviver com a pobreza e a marginalização; realidade que perdurou por muito tempo, até que, a partir de políticas públicas criadas, sobretudo, pelo governo do ex-presidente Luiz Inácio Lula da Silva, foram criadas exitosas políticas públicas no Brasil, a exemplo do sistema de cotas, que possibilitou os afrodescendentes a ocuparem vagas nas universidades. Foram criados também programas de distribuição de renda, como o Bolsa Família, e a expansão e a interiorização do ensino superior, com a criação de novas universidades e institutos federais e programas de permanência estudantil, para que pessoas de origem popular não apenas tivessem acesso, mas condições de concluir o seu curso.

A colonização foi perversa, em suas múltiplas faces, pois colonizou sobretudo o pensamento dos colonizados, levando-os a reconhecerem como "civilizado" e "digno de admiração" apenas o que é de origem portuguesa. Isso fica evidente no plano linguístico em que há uma valorização, no espaço escolar e no imaginário social, de uma tradição gramatical que reflete a norma europeia e um perverso preconceito linguístico, que nada mais é do que o reflexo de uma sociedade marcada por uma mentalidade escravocrata, contra as variantes de origem popular.

Consoante ao pensamento de Faraco, uma prática pedagógica pautada na pedagogia da variação linguística precisa compreender que a heterogeneidade linguística é espelho da heterogeneidade social. Desse modo, as aulas de língua portuguesa têm três objetivos a cumprir no que diz respeito à variação linguística: i) conhecer e entender; ii) entender e respeitar; iii) entender e transitar com 


\section{REVISTA DA ABRALIN}

segurança. Segundo o conferencista, devido aos fatores sócio-históricos, tais objetivos encontram barreiras para a sua concretização e a pedagogia que reconheça a variabilidade como legítima é vista como utópica. Para exemplificar sua fala, menciona a famosa polêmica em torno do livro didático, "Por uma vida melhor", que reconhecia variantes linguísticas não prestigiadas socialmente como funcionais e afirmando, por um prisma científico, que era legítima e não havia "erro".

Comumente, há um falso entendimento de que os sociolinguistas, ao defenderem um ensino pautado em evidências científicas e não em uma visão normativista, são a favor "do vale tudo". Tal premissa é inverídica, pois o que se propõe é uma norma de referência não artificial, que não leve os brasileiros, inclusive os letrados, a uma baixo autoestima linguística, motivada pelo fato de terem que aprender uma norma gramatical anacrônica e que não reflete o uso, seja na fala, seja na escrita monitorada. A norma de referência que deveria ser ensinada na Educação Básica teria que estar relacionada à norma culta brasileira, isto é, aos usos linguísticos consagrados pelos veículos midiáticos tradicionais do país. Em uma sociedade marcada pelo letramento escrito, a escola tem o papel de levar os estudantes a conhecerem e utilizarem com segurança essa variedade de prestígio.

Sobre pesquisas linguísticas que objetivam guiar o ensino de Língua Portuguesa no Brasil com base em uma norma de referência real, o Professor Faraco citou os trabalhos da Professora Doutora Silvia Rodrigues Vieira, docente da UFRJ, com destaque para o seu recém-publicado livro, no qual reúne resultados de trabalhos desenvolvidos por ela e por membros de seu grupo de pesquisa (VIEIRA; LIMA, 2019). No compêndio, a pesquisadora defende a necessidade de não se considerar a fala e a escrita como uma realidade dicotômica, além de defender ser fundamental considerar a existência de diversos gêneros textuais, tanto os da fala quanto os da escrita. Nesse sentido, duas prioridades são destacadas no referido livro: de um lado, a sistematização do comportamento de variedades consoante o continuum compósito fala-escrita e a monitoração estilística; de outro lado, o desenvolvimento de metodologias para a abordagem das regras variáveis em sala de aula.

Ao elencar o referido continuum, mapeando detalhadamente fenômenos morfossintáticos em diversos gêneros de fala e escrita contemporâneos, é possível alcançar generalizações que permitam descrever melhor a distribuição das variantes nos espaços das duas modalidades da língua em seus diversos gêneros, fazendo-se reflexões que permitam cumprir a norma de referência utilizada, em variados estilos. Desse modo, fica patente o salto qualitativo em relação aos objetivos elencados no Projeto Norma Urbana Culta (Projeto NURC), que, embora também buscasse detectar a norma realmente utilizada pelas pessoas altamente escolarizadas no Brasil, não considerava a diversidade de estilos nas duas modalidades da língua.

Com a divulgação da conferência, em uma plataforma digital aberta e interativa, a ABRALIN brinda os seus sócios e o público em geral com uma das melhores reflexões sobre a problemática que envolve ensinar português a falantes nativos no Brasil, especialmente no que tange a aspectos que envolvem o domínio da norma linguística de referência. Embora o tema ocupe a agenda de educadores e linguistas há muito no Brasil, ele permanece atual e ainda necessitando de atenção nos planos teórico e metodológico. A contribuição dada pelo conferencista foi muito significativa, por dois motivos principais: por situar a questão em sólidas bases sócio-histórico-culturais e por chamar 


\section{REVISTA DA ABRALIN}

a atenção para a necessidade de a norma de referência ser alicerçada em resultados empíricos, os quais, passados mais de quarenta anos de pesquisa sociolinguística no Brasil, já podem ser considerados razoáveis, notadamente no que concerne aos usos linguísticos urbanos.

\section{REFERÊNCIAS}

BASES para uma pedagogia da variação linguística. Conferência apresentada por Carlos Alberto Faraco [S.l., S.n], 2020. 1 vídeo (1h 09min 15s). Publicado pelo canal da Associação Brasileira de Linguística. Disponível em: https://www.youtube.com/watch?v=3kS-RHie0Zw. Acesso em: 10 maio 2020.

LUCCHESI, Dante. Língua e sociedade partidas: a polarização sociolinguística do Brasil. São Paulo: Contexto, 2015 .

MATTOS E SILVA, Rosa Virgínia. Ensaios para uma sócio-história do português brasileiro. São Paulo: Parábola Editorial, 2004.

VIEIRA, Silvia Rodrigues; LIMA, Monique Débora Alves de Oliveira. Variação, gêneros textuais e ensino de Português: da norma culta à norma-padrão. Rio de Janeiro: Letras UFRJ, 2019. Disponível em: https://drive.google.com/file/d/19RB04Zf3pzsGHW_sL19HNVO9VV5ug75I/view. Acesso em: 10 maio 2020. 